This is the peer reviewed version of the following article: Phe, R.Z.H. and Skelton, B.W. and Massi, M. and Ogden, M.I. 2020. Influence of the para-Substituent in Lanthanoid Complexes of Bis-Tetrazole-Substituted Calix[4]arenes. European Journal of Inorganic Chemistry. 2020 (1): pp. 94-100, which has been published in final form at 10.1002/ejic.201900877. This article may be used for non-commercial purposes in accordance with Wiley Terms and Conditions for Use of Self-Archived Versions.

\title{
Influence of the para-substituent in lanthanoid complexes of bis- tetrazole substituted calix[4]arenes
}

\author{
Rene Z.H. Phe, ${ }^{[a]}$ Brian W. Skelton, ${ }^{[b]}$ Massimiliano Massi ${ }^{*}[a]$ and Mark I. Ogden, ${ }^{*}[a]$ \\ [a] School of Molecular and Life Sciences and Curtin Institute for Functional Molecules and \\ Interfaces, Curtin University, Kent Street, Bentley 6102 WA, Australia. \\ [b] School of Molecular Sciences, M310, University of Western Australia, Crawley 6009 WA, \\ Australia. \\ *E-mail: $\underline{\text { m.massi@curtin.edu.au; m.ogden@curtin.edu.au }}$ \\ https://staffportal.curtin.edu.au/staff/profile/view/M.Massi/ \\ https://staffportal.curtin.edu.au/staff/profile/view/M.Ogden/
}

\section{Abstract}

5,11,17,23-Tetra-tert-butyl-25,27-dihydroxy-26,28-bis(tetrazole-5-ylmethoxy)calix[4]arene has been reported to form remarkable Ln19 and Ln12 elongated clusters, upon addition of aqueous ammonium carboxylates. The impact of the para substituent on lanthanoid cluster formation has been studied by synthesising two new bis-tetrazole calixarenes, with $p-\mathrm{H}$, and $p$-allyl substituents. Solution phase dynamic light scattering measurements of the reaction mixtures indicated that clusters are not formed with the $p-\mathrm{H}$ and $p$-allyl derivatives, in contrast with the behaviour of the $t$-butyl analogue. Lanthanoid complexes of the $p-\mathrm{H}$ and $p$ allyl calixarenes were characterised by single crystal X-ray diffraction, and were found to form mononuclear complexes, linked to form a one-dimensional coordination polymer for the $p$ allyl system. All of the complexes were isolated as ammonium salts, with ammonium cation included in the calixarene cavity in most cases. It is concluded that the nature of the para substituent has a profound impact on the lanthanoid cluster formation process, and derivatives with more subtle structural changes will be required to determine if additional lanthanoid "bottlebrush" clusters can be isolated.

Keywords: Calixarenes; Lanthanides; Supramolecular Chemistry 


\section{Introduction}

The unique photophysical and magnetic properties of the lanthanoid ions continue to drive interest in the coordination and structural chemistry of these elements. The formation of lanthanoid clusters is a particular challenge for the synthetic chemist, with the outcomes of specific lanthanoid-ligand combinations still very difficult to predict in general, although some systems are relatively well understood. ${ }^{[1]}$

We have previously reported the isolation of an unexpected elongated $\operatorname{Ln} 19$ "bottlebrush" cluster when the bis-tetrazole calix[4]arene $\mathbf{1}$ was allowed to react with a lanthanoid precursor (Eu - Lu) with addition of an aqueous ammonium acetate buffer solution (Figure 1)..$^{[2]}$ In contrast, when triethylamine was added to deprotonate the calixarene, rather than ammonium acetate, a mononuclear complex was isolated. ${ }^{[3]}$ These results emphasised the structural versatility of the tetrazole moiety, which is often found in the second coordination sphere of lanthanoid complexes, even when incorporated in a polydentate ligand. ${ }^{[4]}$ The high aspect ratio of the Ln19 cluster was particularly striking, as in general large coordination clusters tend towards regular polyhedral[5] or spherical geometries, ${ }^{[6]}$ or molecular "wheels". ${ }^{[7]}$ Given the Ln19 cluster is "coated" with the calixarene with the tert-butyl groups directed outwards, it seemed plausible that the para-substituent of the calixarene might have a significant impact on the cluster formation. To test this hypothesis, the syntheses of related bis-tetrazole ligands $\mathbf{2}$, and $\mathbf{3}$ (Figure 1) were undertaken, where the para-substituents were selected to be readily accessible, and with varying hydrophobicity. We report here the synthesis and characterisation of these ligands, and their complexation behaviours with lanthanoid cations. 

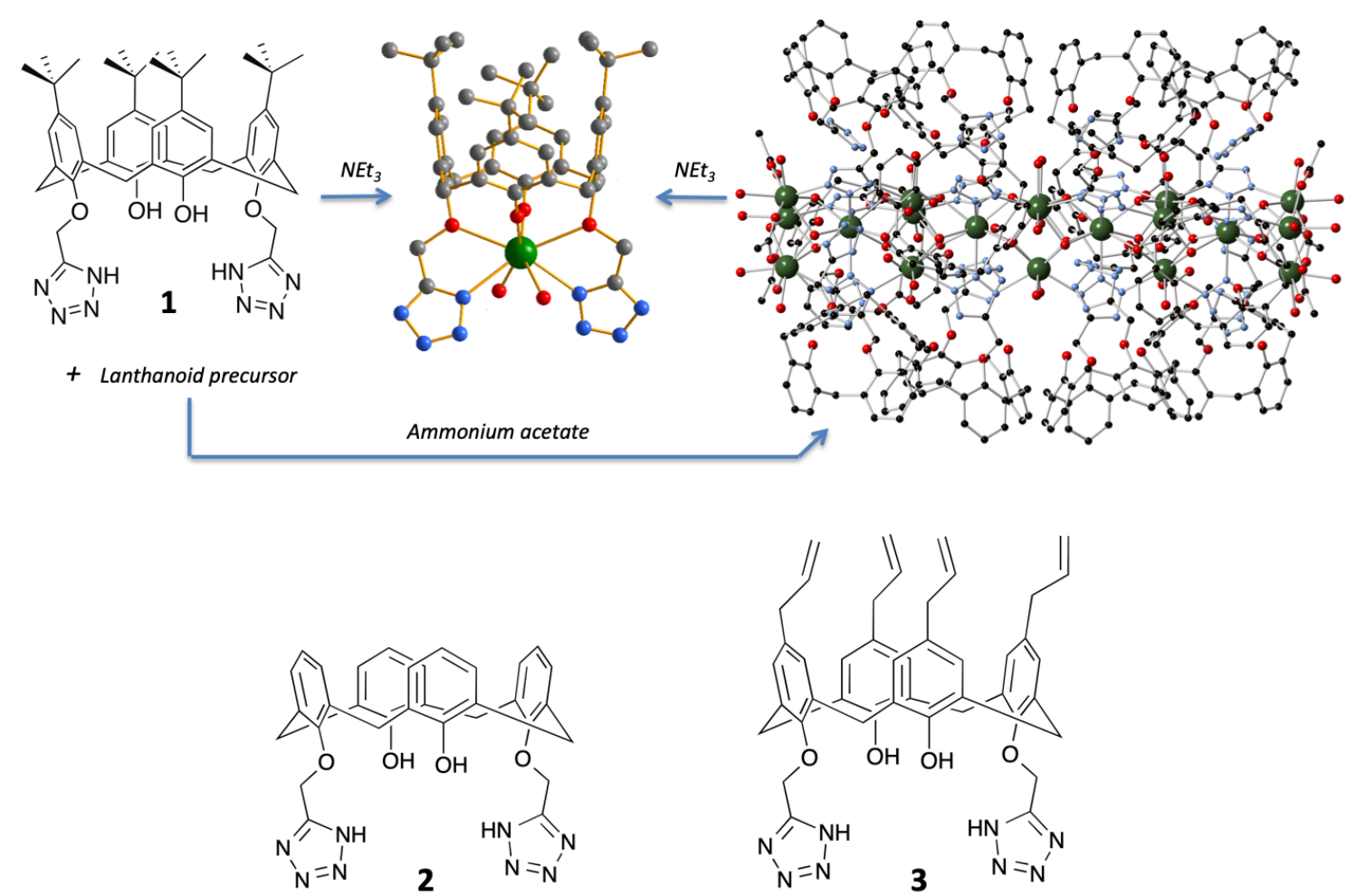

Figure 1. Scheme showing the formation of mononuclear and Ln19 "bottlebrush" complexes with $\mathbf{1},{ }^{[2-3]}$ and the structures of the target calixarene ligands $\mathbf{2}$, and $\mathbf{3}$.

\section{Results and Discussion}

\section{Ligand Syntheses}

Calixarenes 2, and $\mathbf{3}$ were synthesised using well established protocols, proceeding by alkylation of the phenol rim to introduce the nitrile moiety, followed by conversion of the nitrile to the tetrazolate using the method reported by Koguro, ${ }^{[8]}$ as described previously for 1 (see Supplementary Information). ${ }^{[3]}$ Calixarene $\mathbf{2}$ has been reported previously, ${ }^{[9]}$ synthesised by a different method as a control for para-phenylazo bis-tetrazole calixarenes that were exploited as colorimetric sensors for calcium ions. We note that the Koguro reaction to form 2 required careful temperature control at $70{ }^{\circ} \mathrm{C}$ to ensure the product formed without conformational mixing. Derivative $\mathbf{3}$ was more problematic as the intermediate nitrile was not able to be purified in our hands. The impure material was nevertheless used for the 
conversion to the tetrazole, providing a product that was sufficiently pure for metal complexation studies (see Supplementary Information).

\section{Metal Complexation}

We have reported the use of dynamic light scattering to monitor solution-phase cluster formation under conditions that were found to result in crystallisation of the Ln19 "bottlebrush" clusters. A distinct increase in the average particle size was observed upon addition of the aqueous ammonium carboxylate solution to a mixture of $\mathbf{1}$ and a lanthanoid salt dissolved in 1:1 ethanol:ethyl acetate. ${ }^{[2]}$ A similar approach was taken here, with the intent that DLS would provide a simple and readily accessible technique to observe potential cluster formation in the reaction mixtures. With ligands $\mathbf{2}$ and $\mathbf{3}$, no significant increases in average particle size were observed in comparison to 1 (see Figure S6, S7), suggesting any cluster formation is much less than occurs with 1.

Despite these observations, attempts were then made to crystallise complexes from the reaction mixtures. Given the lability of the lanthanoid cations, it is plausible that clusters could be formed below the detection limit of the DLS technique, which may nevertheless be isolable, depending on the relative solubilities of the species present in the reaction mixture. Considering first calixarene $\mathbf{2}$, no crystalline materials were obtained from ethanol:ethyl acetate solvent mixtures. Using ethanol as the solvent gave a crystalline material for the Eu system, albeit in low yield and with poor reproducibility. Moving away from solvents which have been found to support the bottlebrush cluster formation, use of acetonitrile was more successful, with crystalline materials isolated in good yield for $\mathrm{Ln}=\mathrm{Nd}, \mathrm{Gd}, \mathrm{Eu}, \mathrm{Dy}, \mathrm{Er}$ and $\mathrm{Yb}$. Single crystal X-ray structure determinations showed that these compounds are isomorphous. Therefore, here we will only discuss the two Eu complexes of $\mathbf{2}$ in detail. 
The results of the crystal structure determinations were consistent with the DLS studies in solution, with mononuclear complexes crystallising from both ethanol and acetonitrile. The complex crystallised from ethanol was formulated as $\left(\mathrm{NH}_{4}\right)[\mathrm{Eu}(\mathbf{2}-$ $\left.4 \mathrm{H})(\mathrm{HOEt})_{2}\right] \cdot 2 \mathrm{EtOH}$, and from acetonitrile as $\left(\mathrm{NH}_{4}\right)\left[\mathrm{Eu}(2-4 \mathrm{H})\left(\mathrm{OH}_{2}\right)_{2}\right] \cdot \mathrm{CH}_{3} \mathrm{CN} \cdot \mathrm{H}_{2} \mathrm{O}($ where $(24 \mathrm{H})$ is the fully deprotonated calixarene). In both complexes, the four phenol-O atoms, and two tetrazole- $\mathrm{N}$ atoms of the calixarene are coordinated to the metal centre, with the first coordination sphere completed by two O-donor solvent molecules, as reported for the complexes of $\mathbf{1}$ where triethylamine was used to deprotonate the calixarene (Figure 1)..$^{[3]}$ In the present examples, however, the complexes are anionic rather than neutral, with the required counter-cation being an ammonium ion.

The structure of the ethanol solvate has two different molecules in the unit cell, one on a crystallographic 2-fold axis (molecule 2). The metal coordination is similar in both molecules, but an ammonium cation is situated in the calixarene cavity of molecule 1, whereas a solvent ethanol molecule occupies a similar position in molecule 2 (Figure 2). Inclusion of an ammonium cation in the calix[4]arene cavity has been reported previously, most notably as a part of an $\mathrm{N}_{2} \mathrm{H}_{7}{ }^{+}$assembly stabilised by calix[4]arene. ${ }^{[10]}$ Inclusion in $p$-sulfonatocalix[4]arene has also been reported, although the protons of the cation were not located. ${ }^{[11]}$ In both of these examples, there appears to be no significant interaction between the ammonium cation and the calixarene framework. In contrast, here the disposition of ammonium cation is consistent with a hydrogen bond between the ammonium cation and a phenol $\mathrm{O}$ atom (N1...O21, 3.159(7) Å). While hydrogen bonds between primary alkyl ammonium cations and phenol $O$ atoms of larger calix[5]arene ${ }^{[12]}$ and calix[6]arene ${ }^{[13]}$ hosts are well 
established, such interactions are rare in calix[4]arenes. ${ }^{[14]}$ The hydrogen bond interaction in the present case is facilitated by the "pinched" cone conformation of the calixarene, where the dihedral angles between the phenyl rings and the $\left(\mathrm{CH}_{2}\right)_{4}$ are $75.0(2), 75.5(2)^{\circ}$ for rings 1 and 3 and $30.7(2)$ and $31.2(2)^{\circ}$ for rings 2 and 4 of molecule 1. Molecule 2, which does not have a guest interacting through a hydrogen bond is somewhat less pinched, with dihedral angles of $74.6(2)$ and $41.5(2)^{\circ}$ for rings 5 and 6. The second ammonium cation is positioned in the lattice between molecules 1 and 2, forming part of a complex hydrogen bond network (see Figures S8, Table S1).

(a)

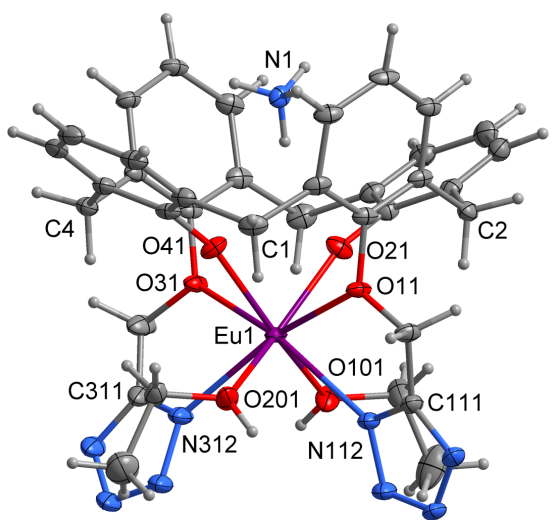

(b)

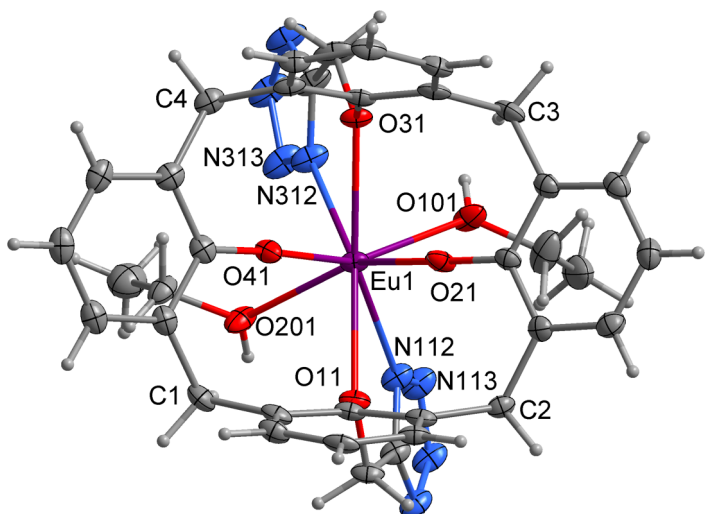

(c)

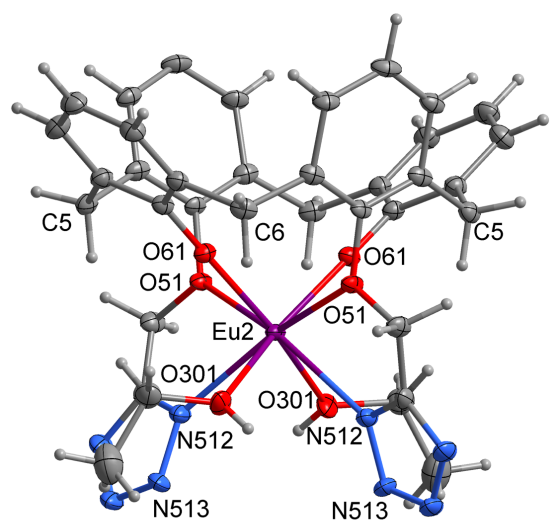

(d)

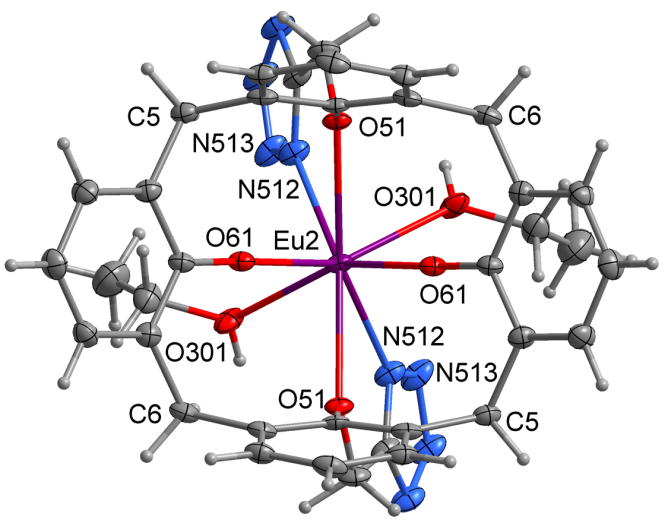

Figure 2. Structure of $\left(\mathrm{NH}_{4}\right)\left[\mathrm{Eu}(2-4 \mathrm{H})(\mathrm{HOEt})_{2}\right]$, molecule 1 of projected (a) approximately onto the $\left(\mathrm{CH}_{2}\right)_{4}$ plane showing the ammonium ion, (b) oblique to the $\left(\mathrm{CH}_{2}\right)_{4}$ plane, and molecule 2 projected (c) onto the $\left(\mathrm{CH}_{2}\right)_{4}$ plane, and (d) oblique to the $\left(\mathrm{CH}_{2}\right)_{4}$ plane. Atomic displacement ellipsoids are drawn at the $50 \%$ probability level in this and subsequent figures.

The complex crystallised from acetonitrile, $\left(\mathrm{NH}_{4}\right)\left[\mathrm{Eu}(2-4 \mathrm{H})\left(\mathrm{OH}_{2}\right)_{2}\right] \cdot \mathrm{CH}_{3} \mathrm{CN} \cdot \mathrm{H}_{2} \mathrm{O}$, is somewhat simpler with one unique complex anion. The structure is similar to the ethanol solvate, with a mononuclear complex anion, and the ammonium cation 
positioned within the calixarene cavity (Figure 3 ). The coordinated ethanol molecules are replaced by water. The calixarene conformation is pinched where dihedral angles between the phenyl rings and the $\left(\mathrm{CH}_{2}\right)_{4}$ are $77.7(2), 79.3(2)^{\circ}$ for rings 1 and 3 and $41.4(2)$ and $29.4(2)^{\circ}$ for rings 2 and 4 . The most inclined phenyl ring 4 is also associated with the phenol $\mathrm{O}$ atom hydrogen bond to the ammonium cation ((N1...O41, 2.792(2) $\AA$ ). Amongst numerous hydrogen bond interactions in the structure, the complex anions are linked as dimers by four hydrogen bonds between the coordinated water molecules and $\mathrm{N}$ atoms of the neighbouring tetrazole moieties (see Figure S9, Table S2). These complexes crystallised readily from acetonitrile, and nine members of the isomorphous series were structurally characterised. Aside from the solvating water molecule requiring a disordered model for later members of the series, the changes across the series are as expected, with the metal-ligand bond distances decreasing steadily across the series (see Table S3).

(a)

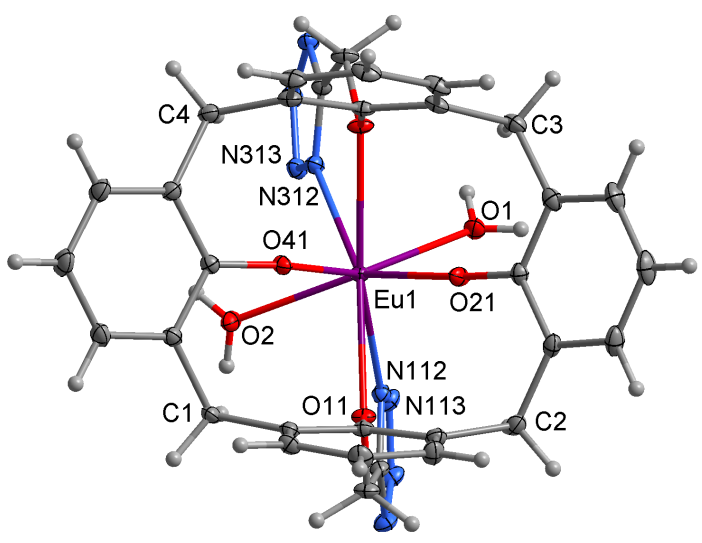

(b)

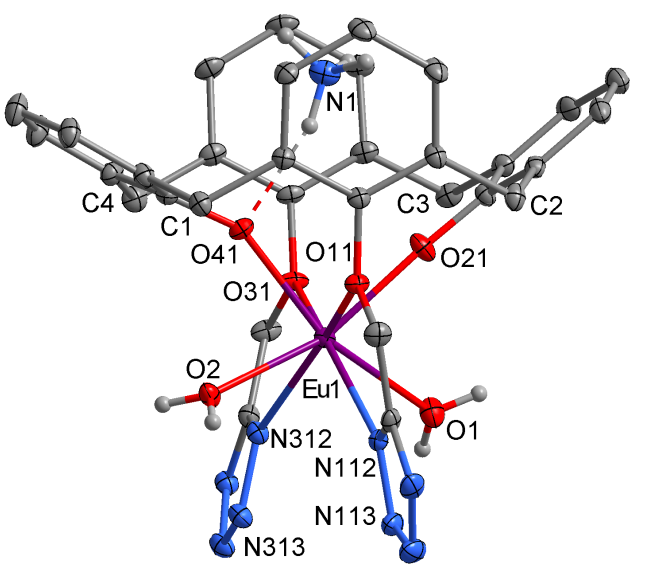

Figure 3. Structure of $\left(\mathrm{NH}_{4}\right)\left[\mathrm{Eu}(2-4 \mathrm{H})\left(\mathrm{OH}_{2}\right)_{2}\right],(\mathrm{a})$ the anion projected onto the plane of the methylene groups, and (b) the structure with ammonium ion, showing the hydrogen bond between the ammonium ion and the phenolate oxygen atom.

Complexes of allyl-substituted calixarene $\mathbf{3}$ formed single crystals from ethanol/ethyl acetate solvent mixtures, upon addition of aqueous ammonium carboxylates. Consistent with 
the DLS measurements in solution, the crystals that deposited were not composed of large clusters. Instead, one-dimensional coordination polymers are formed with a bond from one of the tetrazole units to the metal atom of the molecule related by the crystallographic $c$-glide plane. The resulting complex is formulated as $\left\{\left(\mathrm{NH}_{4}\right)[\mathrm{Eu}(3-4 \mathrm{H})(\mathrm{HOEt})] \cdot 3 \mathrm{EtOH}\right\}_{n}$. Figure 4 shows the structure, where it can be seen that the ammonium ion and, to some extent, the water molecule and one ethanol molecule are situated within the calix. Details for the full hydrogen bond array found in the structure are given in Table S4 and Figure S10. An isomorphous solvate, $\left\{\left(\mathrm{NH}_{4}\right)[\mathrm{Eu}(3-4 \mathrm{H})(\mathrm{HOEt})] \cdot 2 \mathrm{EtOH} \cdot \mathrm{H}_{2} \mathrm{O}\right\}_{n}$, was also crystallised where the water molecule has been replaced by another ethanol molecule. They are in different hands in the non-centrosymmetric space group $C c$, but do not otherwise differ significantly.

(a)

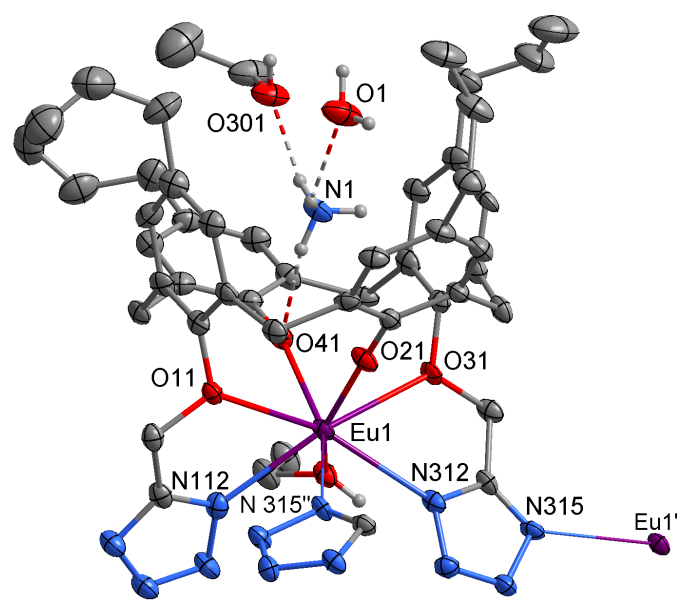

(b)

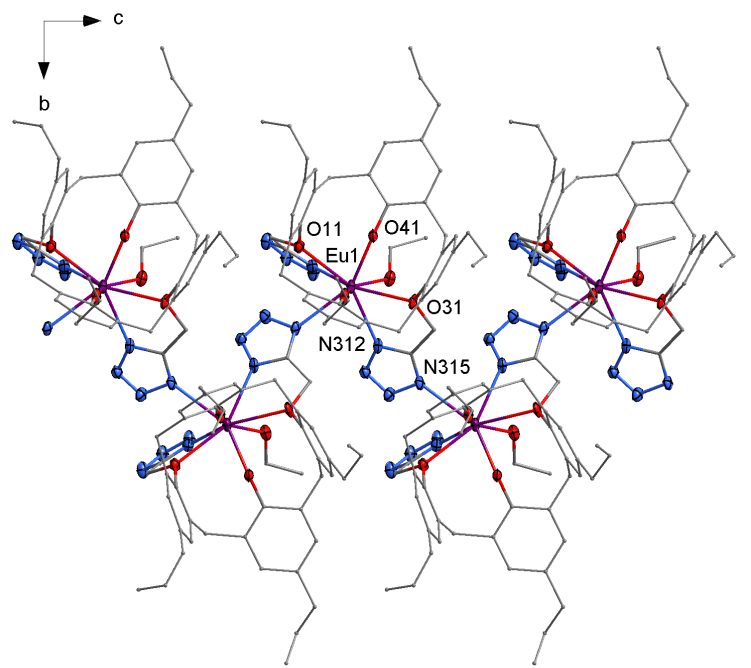

Figure 4. (a) Structure of the monomeric unit of $\left\{\left(\mathrm{NH}_{4}\right)[\mathrm{Eu}(3-4 \mathrm{H})(\mathrm{HOEt})] \cdot 2 \mathrm{EtOH} \cdot \mathrm{H}_{2} \mathrm{O}\right\}_{n}$, showing the hydrogen bonding to the ammonium ion and solvents in the calix. The primed atom is at $x, 1-y, 1 / 2+z$; double primed atom is at $x, 1-y, z-1 / 2$. Hydrogen atoms not involved have been omitted. (b) The structure projected along the $a$-axis showing the polymer. Hydrogen atoms, the solvent molecules and the ammonium ion have been omitted]

The DLS results suggest that this coordination polymer does not form to any significant extent in solution, and so is presumably formed upon crystallisation. The complexes of $\mathbf{3}$ did not crystallise as readily as those of $\mathbf{2}$, with only the ethanol/ethyl acetate solvent mixture giving 
useful products. A Nd complex was crystallised as the $2 \mathrm{EtOH} \cdot \mathrm{H}_{2} \mathrm{O}$ solvate, and $\mathrm{Gd}$ complex was crystallised as the $3 \mathrm{EtOH}$ solvate. Subtle changes in the crystallisation conditions presumably give rise to the different solvates.

\section{Photophysical Properties}

We have previously reported that calixarene 1 was a viable antenna molecule for terbium, and to a much lesser extent europium, based on solution phase studies. ${ }^{[3]}$ Here we were able to carry out solid-state studies of the Ln complexes of $\mathbf{2}$ isolated from acetonitrile solution, as these materials were relatively stable upon isolation under ambient conditions. Solution phase measurements were also carried out for comparison (see SI).

The solid materials were excited at $\lambda_{\mathrm{ex}}=300 \mathrm{~nm}$, resulting in the line-like emissions typical of the specific lanthanide. As expected based on our previous work, terbium ions were effectively excited giving the spectrum shown in Figure 5.

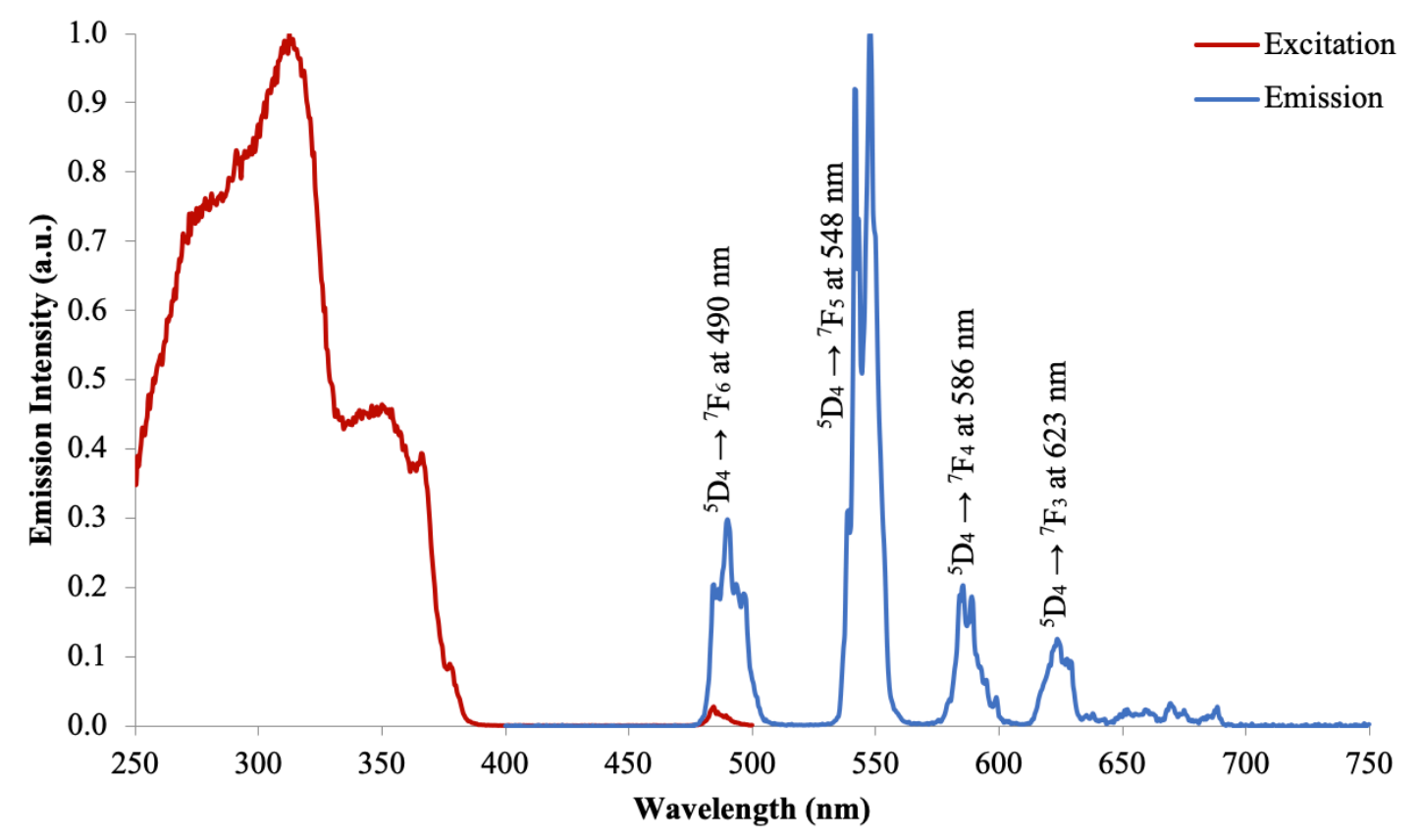

Figure 5. Normalised excitation and emission spectra of $\mathrm{NH}_{4}\left[\mathrm{~Tb}(2-4 \mathrm{H})\left(\mathrm{OH}_{2}\right)_{2}\right]$. 
The transfer of energy from the triplet state of the calixarene acting as an antenna is evidenced by the broad bands in the $250-350 \mathrm{~nm}$ region of the excitation spectrum. However, in the case of Eu and Dy, significant direct excitation of the lanthanoid cations is also present along with the typical broader bands belonging to the calixarene ligand, indicating the sensitisation in these systems is somewhat less efficient (Figures 6,7). An analysis of the spectrum of the Eu displays a stronger intensity for the hypersensitive ${ }^{5} D_{0} \rightarrow{ }^{7} F_{2}$ peak compared to the magnetic allowed ${ }^{5} D_{0} \rightarrow^{7} F_{1}$ peak, indicating relatively low symmetry for the Eu centre. The ${ }^{5} D_{0} \rightarrow{ }^{7} F_{0}$ is also visible, albeit of the expected low intensity. This peak is narrow, suggesting emission from a unique Eu centre in the structure. In the case of $\mathrm{Yb}$ (Figure 8), the typical near-infrared band corresponding to the ${ }^{2} \mathrm{~F}_{5 / 2} \rightarrow{ }^{2} \mathrm{~F}_{7 / 2}$ is observed, with the excitation spectrum demonstrating sensitisation from the calixarene ligand. The band is split into three peaks due to crystal field influence, and hot bands are also visible around $950 \mathrm{~nm}$.

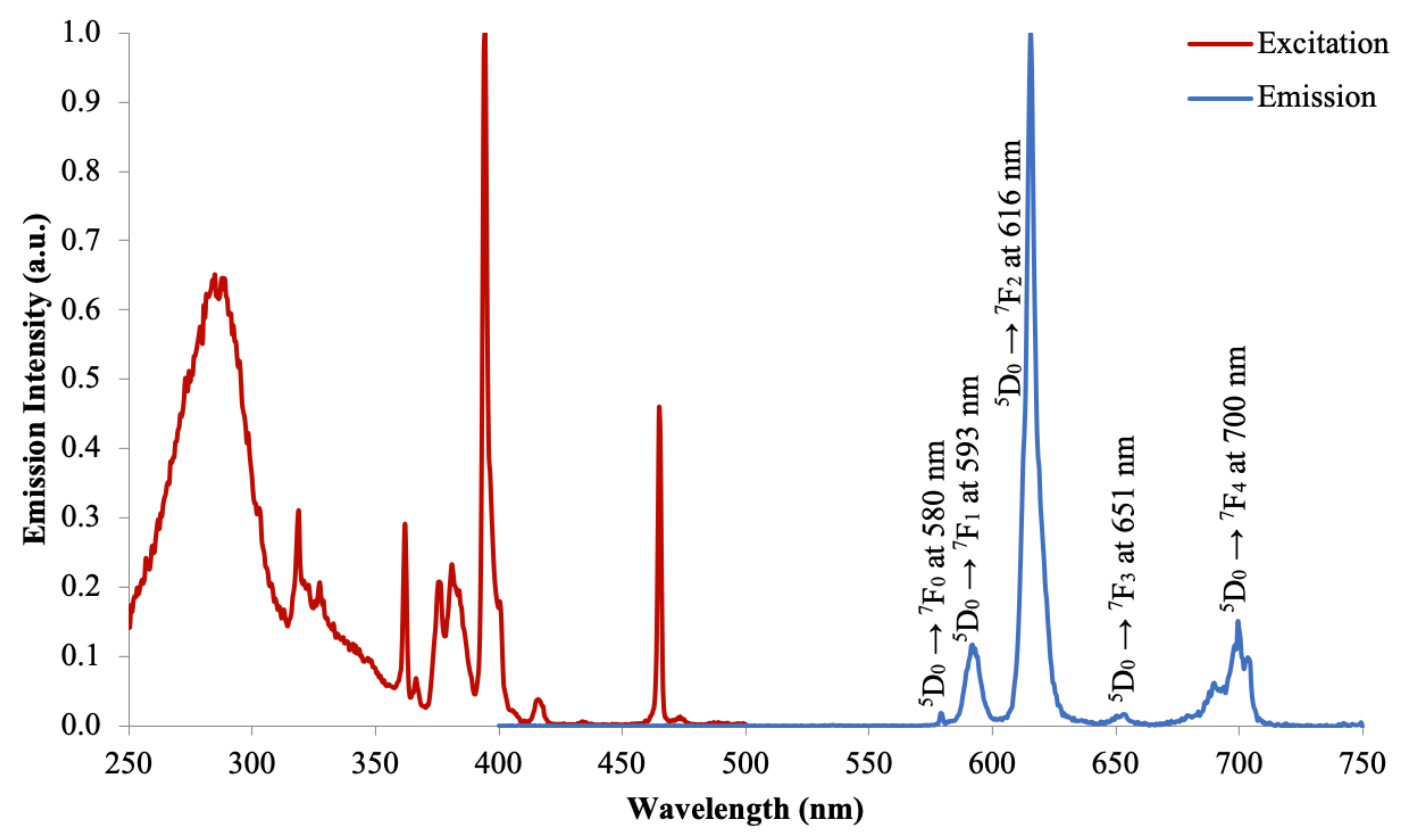

Figure 6. Normalised excitation and emission spectra of $\mathrm{NH}_{4}\left[\mathrm{Eu}(2-4 \mathrm{H})\left(\mathrm{OH}_{2}\right)_{2}\right]$. 


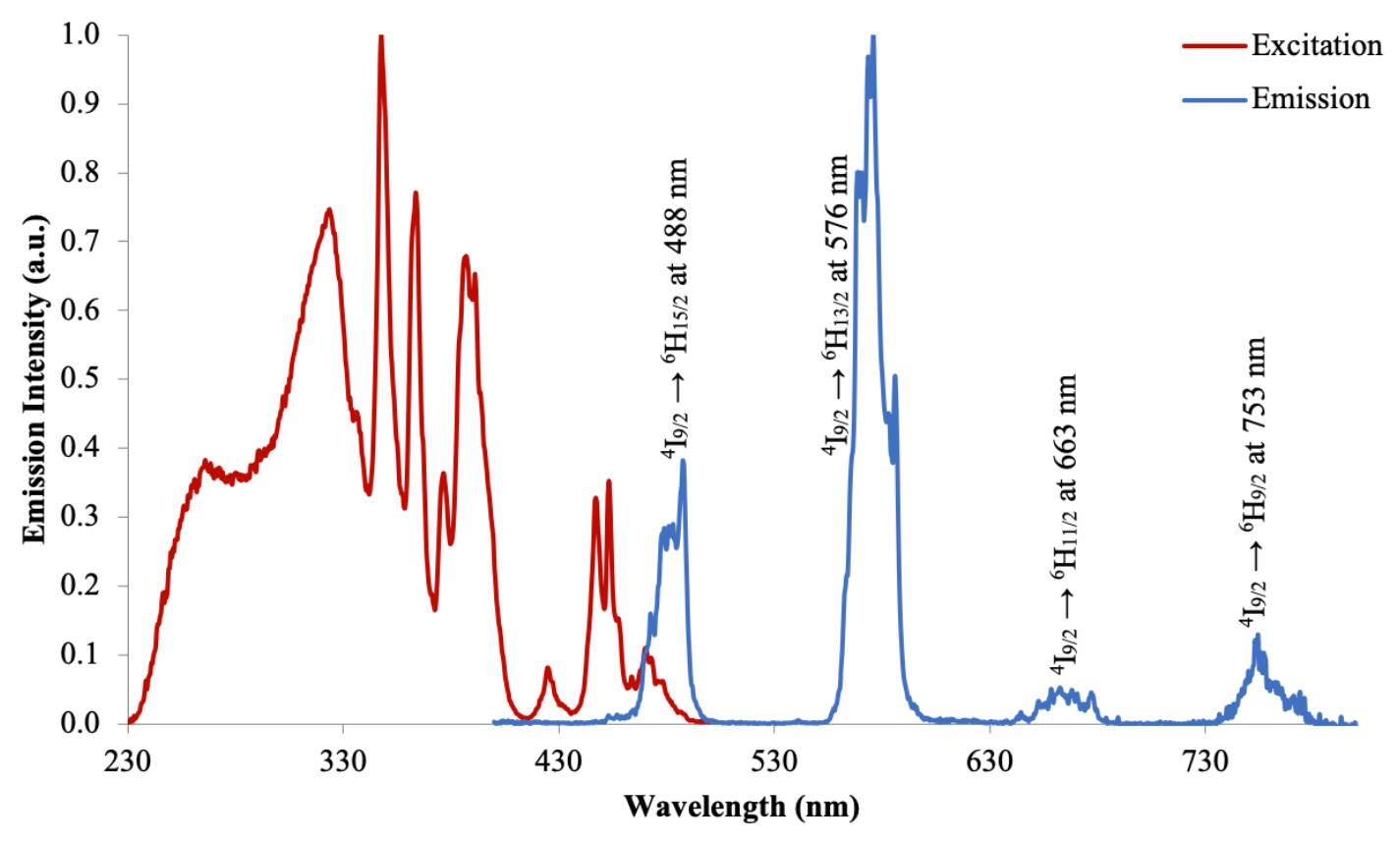

Figure 7. Normalised excitation and emission spectra of $\mathrm{NH}_{4}\left[\mathrm{Dy}(2-4 \mathrm{H})\left(\mathrm{OH}_{2}\right)_{2}\right]$.

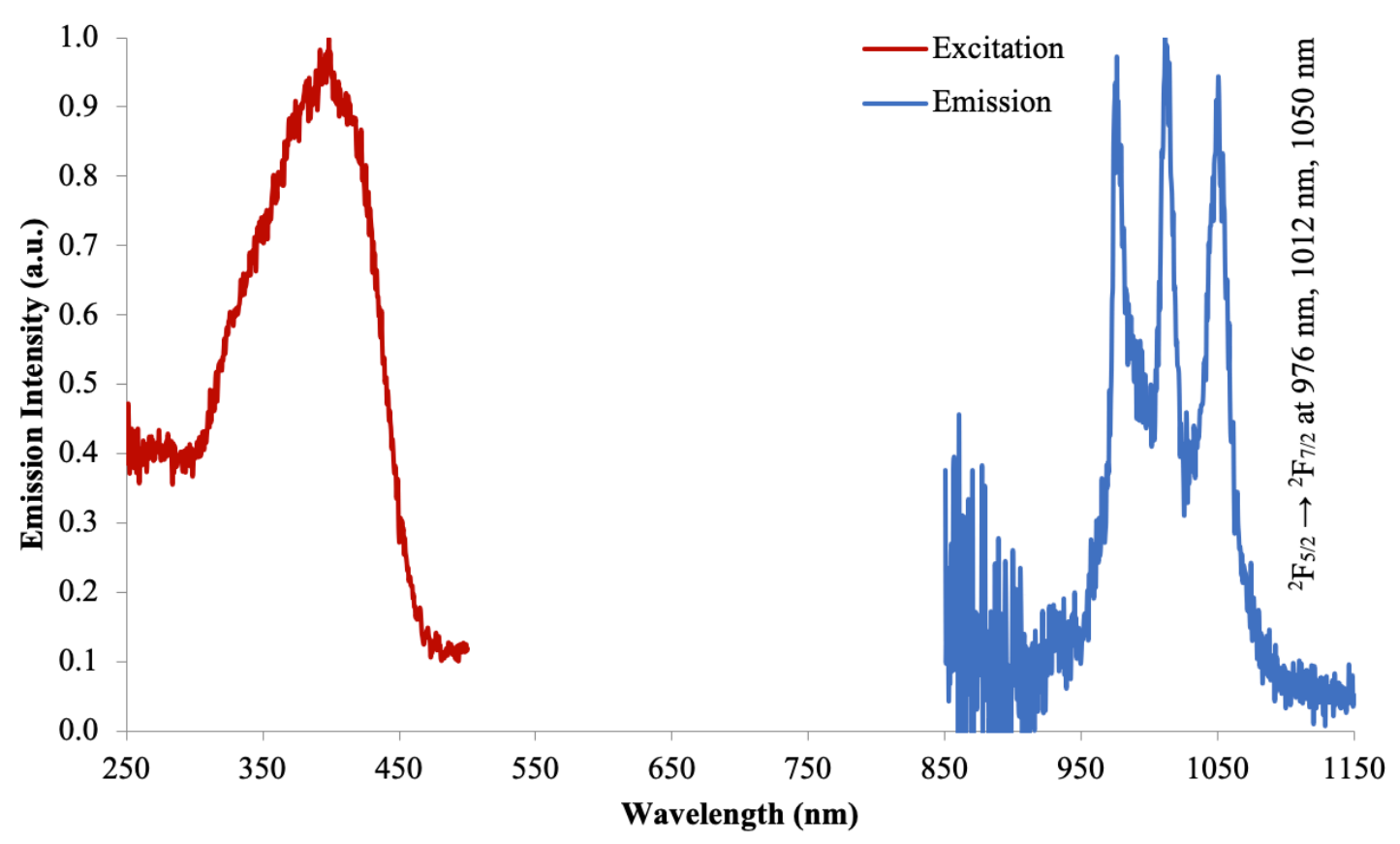

Figure 8. Normalised excitation and emission spectra of $\mathrm{NH}_{4}\left[\mathrm{Yb}(2-4 \mathrm{H})\left(\mathrm{OH}_{2}\right)_{2}\right]$. 


\section{Conclusions}

It has been shown that the para substituent of bis-tetrazole functionalised calixarenes has a significant impact on formation of the lanthanoid clusters known to form with the $p$-t-butyl derivative 1. Reducing the lipophilicity by removing the t-butyl group, or replacing it with allyl substituents resulted in the crystallisation of mononuclear complexes. Dynamic light scattering measurements also indicated that clusters did not form to a significant extent in the reaction mixtures. The responsiveness of the system to the nature of the para-substituent suggests that more subtle changes will be needed to isolate new "bottlebrush" clusters supported by tetrazole-functionalised calixarenes. While unrelated to cluster formation, the consistent inclusion of the ammonium cation in the calixarene cavity, stabilised by a hydrogen bond, suggests that these complexes may be interesting to investigate as receptors for this cation.

\section{Experimental}

\section{General procedures}

All reagents and solvents were purchased from chemical suppliers and used as received without further purification. Infrared spectra (IR) were recorded on solidstate samples using an attenuated total reflectance Perkin Elmer Spectrum 100 FT-IR. The spectra were recorded from 4000 to $650 \mathrm{~cm}^{-1}$. The intensity of the IR bands is reported as strong (s), medium (m), or weak (w), with broad (br) bands also specified. Melting points were determined using a BI Barnsted Electrothermal 9100 apparatus. Elemental analyses were obtained using a Perkin Elmer PE 2400 CHN Elemental Analyser at Curtin University, Australia. Nuclear magnetic resonance (NMR) spectra were recorded using a Bruker Avance 400 spectrometer $\left(400.1 \mathrm{MHz}\right.$ for ${ }^{1} \mathrm{H} ; 100 \mathrm{MHz}$ 
for ${ }^{13} \mathrm{C}$ ) at $300 \mathrm{~K}$. The data were acquired and processed by the Bruker TopSpin 3.1 software. All of the NMR spectra were calibrated to residual solvent signals. Details of the syntheses of $\mathbf{2}$, and $\mathbf{3}$, and the $\operatorname{Ln}\left(\mathrm{NO}_{3}\right)_{3}(\mathrm{DMSO})_{3}{ }^{[15]}$ salts are given in the Supplementary Information. Solution phase light scattering measurements were carried out as described previously. ${ }^{[2]}$

Absorption spectra were recorded using a Perkin Elmer Lambda 35 UV/Vis spectrophotometer in solution state at room temperature. Steady state excitation and emission spectra were uncorrected and recorded using a FLSP980-S2S2-stm Edinburgh spectrofluorometer equipped with: a) a temperature monitored cuvette holder; b) 450 W Xenon arc lamp; c) double excitation and emission monchromators; d) a Peltier cooled Hamamatsu R928P photomultiplier tube for detection of visible radiation (spectral range 200-870 $\mathrm{nm}$ ); and e) a Hamamatsu R5509-42 photomultiplier for detection of NIR radiation (spectral range $800-1400 \mathrm{~nm}$ ). Emission and excitation spectra were corrected for source intensity (lamp and grating) and emission spectral response (detector and grating) by a calibration curve supplied with the instrument.

\section{Synthesis of Lanthanoid Complexes}

The following procedures describe the synthesis of complexes of $\mathbf{2}$ and $\mathbf{3}$ which were characterised using single crystal X-ray crystallography. The isolated complexes were dried and subject to microanalysis which revealed changes in solvation upon isolation, as is typical for calixarene complexes. These results are tabulated in the Supplementary Information. General Procedure for Crystallisation of Complexes of 2 from Ethanol Complexes were crystallised by the slow cooling of hot $95 \%$ ethanol ( $20 \mathrm{~mL})$, containing the debutylated di tetrazole calixarene ligand $(29 \mathrm{mg}, 0.05 \mathrm{mmol})$ and $\mathrm{Ln}\left(\mathrm{NO}_{3}\right)_{3}(\mathrm{DMSO})_{3}(0.06 \mathrm{mmol})$ along with five equivalents of aqueous ammonium 
carboxylate (acetate or benzoate) $(1 \mathrm{M}, 250 \mu \mathrm{L})$ over $24 \mathrm{hr}$. Only in the case of the Eu salt, did clear cubic block shaped crystals suitable for single crystal X-ray structure determination deposit on standing. Yields were variable (5-25\%).

General Procedure for Crystallisation of Complexes of $\mathbf{2}$ from Acetonitrile

Complexes were crystallised by slow evaporation of acetonitrile $(20 \mathrm{~mL})$, containing the debutylated di tetrazole calixarene ligand $(29 \mathrm{mg}, 0.05 \mathrm{mmol})$ and $\mathrm{Ln}\left(\mathrm{NO}_{3}\right)_{3}(\mathrm{DMSO})_{3}(0.06 \mathrm{mmol})$ along with five equivalents of aqueous ammonium carboxylate (acetate or benzoate) $(1 \mathrm{M}, 250 \mu \mathrm{L})$ over $24 \mathrm{hr}$. Clear or coloured cubic block shaped crystals suitable for single crystal X-ray structure determination deposited in good yield (60-80\%) on standing, for Ln = Eu, Dy, Er and Yb.

General Procedure for Crystallisation of Complexes of $\mathbf{3}$

Complexes were crystallised by the slow evaporation of a $50: 50$ solvent mixture (20 $\mathrm{mL}$ ) of ethyl acetate and $95 \%$ ethanol containing $3(37 \mathrm{mg}, 0.05 \mathrm{mmol}$ ) and $\mathrm{Ln}\left(\mathrm{NO}_{3}\right)_{3}(\mathrm{DMSO})_{3}(0.06 \mathrm{mmol})$ along with five equivalents of aqueous ammonium carboxylate (acetate or benzoate). Clear or coloured needle shaped crystals suitable for single crystal X-ray structure determination deposited in moderate yield (10-25\%) after 2 to 6 weeks of slow evaporation of the solvent, for $\mathrm{Ln}=\mathrm{Gd}$, and $\mathrm{Eu}$ (two solvates).

\section{Crystallography}

Crystallographic data for the structures were collected at $100(2) \mathrm{K}$ on an Oxford Diffraction Gemini or Xcalibur diffractometer fitted with Mo-K $\alpha$ or $\mathrm{Cu}-\mathrm{K} \alpha$ radiation. Following Lp and analytical absorption corrections and solution by direct methods, the structures were refined against $F^{2}$ with full-matrix least-squares using the program SHELXL-2017. ${ }^{[16]}$ 
Unless stated otherwise, anisotropic displacement parameters were employed for the non-hydrogen atoms, and hydrogen atoms were added at calculated positions and refined by use of a riding model with isotropic displacement parameters based on those of the parent atom. The complete crystallographic data for the structures reported in this paper have been deposited at the Cambridge Crystallographic Data Centre with supplementary publication numbers given below. Copies of the data can be obtained free of charge via https://www.ccdc.cam.ac.uk/structures/, or from the Cambridge Crystallographic Data Centre, 12 Union Road, Cambridge CB2 1EZ, U.K.; fax: (+44) 1223-336-033; or e-mail: data request@ccdc.cam.ac.uk

\section{X-ray Data Refinement}

Complex of 2 crystallised from ethanol

$\left(\mathrm{NH}_{4}\right)\left[\mathrm{Eu}(2-4 \mathrm{H})(\mathrm{HOEt})_{2}\right] \cdot 2 \mathrm{EtOH}: \mathrm{C}_{40} \mathrm{H}_{52} \mathrm{EuN}_{9} \mathrm{O}_{8}, M=938.86$, orange prism, $0.085 \mathrm{x}$ $0.069 \times 0.038 \mathrm{~mm}^{3}$, monoclinic, space group $C 2 / c$ (No. 15), $a=33.0628(9), b=$ 19.3808(4), $c=20.6212(8) \AA ̊ \Omega, \beta=104.412(3)^{\circ}, V=12797.9(7) \AA^{3}, Z=12, D_{c}=1.462 \mathrm{~g}$ $\mathrm{cm}^{-3}, \mu=11.029 \mathrm{~mm}^{-1} . F_{000}=5784$, CuK $\alpha$ radiation, $2 \theta_{\max }=135.08^{\circ}, 59306$ reflections collected, 11445 unique $\left(R_{\mathrm{int}}=0.0791\right)$. Final $G o o F=1.065, R 1=0.0633, w R 2=0.1682$, $R$ indices based on 9136 reflections with $I>2 \sigma(I),|\Delta \rho|_{\max }=1.721$ e $\AA^{-3}, 835$ parameters, 43 restraints. CCDC 1920176.

From microanalytical results (see Supplementary Information) and the lack of observed electron density on the tetrazole $\mathrm{N}$ atoms, charge balance was achieved by assigning the residual electron density to ammonium ions, one of which was modelled as being disordered. Ammonium hydrogen atoms were included from electron density and hydrogen bonding considerations and refined with geometries restrained to ideal values. One coordinated ethanol molecule was modelled as being disordered over two 
sets of sites with site occupancies refined to $0.66(2)$ and its complement. The choice of carbon and oxygen atom on this ethanol molecule was made on the basis of intermolecular interactions although $\mathrm{OH}$ hydrogen atoms were not located. The $\mathrm{OH}$ hydrogen atoms on the remaining ethanol molecules were refined with geometries restrained to ideal values. Solvent ethanol geometries were restrained to ideal values. Complexes of 2 crystallised from acetonitrile

$\left(\mathrm{NH}_{4}\right)\left[\mathrm{Eu}(2-4 \mathrm{H})\left(\mathrm{OH}_{2}\right)_{2}\right] \cdot \mathrm{CH}_{3} \mathrm{CN} \cdot \mathrm{H}_{2} \mathrm{O}: \mathrm{C}_{34} \mathrm{H}_{37} \mathrm{EuN}_{10} \mathrm{O}_{7}, M=849.69$, orange needle, $0.482 \times 0.096 \times 0.063 \mathrm{~mm}$, monoclinic, space group $P 2_{1} / n$ (No. 14), $a=9.75840(10), b$ $=18.0227(2), c=19.4959(2) \AA ̊ \Omega, \beta=95.2230(10)^{\circ}, V=3414.56(6) \AA^{3}, Z=4, D_{\mathrm{c}}=1.653 \mathrm{~g}$ $\mathrm{cm}^{-3}, \mu=1.902 \mathrm{~mm}^{-1} . F_{000}=1720$, MoK $\alpha$ radiation, $2 \theta_{\max }=71.02^{\circ}, 95382$ reflections collected, 15005 unique $\left(R_{\text {int }}=0.0401\right)$. Final GooF $=1.050, R 1=0.0266, w R 2=0.0589$, $R$ indices based on 13233 reflections with $I>2 \sigma(I),|\Delta \rho|_{\max }=0.797$ e $\AA^{-3}, 510$ parameters, 13 restraints. CCDC 1920180.

The solvent was modelled as one acetonitrile molecule and one water molecule. $\mathrm{N}-\mathrm{H}$ and O$\mathrm{H}$ hydrogen atoms were located and refined with geometries restrained to ideal values. The ammonium ion was also identified as such on the basis of refinement.

$\left(\mathrm{NH}_{4}\right)\left[\mathrm{Dy}(2-4 \mathrm{H})\left(\mathrm{OH}_{2}\right)_{2}\right] \cdot \mathrm{CH}_{3} \mathrm{CN} \cdot 1.09 \mathrm{H}_{2} \mathrm{O}: \mathrm{C}_{34} \mathrm{H}_{37.18} \mathrm{DyN}_{10} \mathrm{O}_{7.09}, M=861.84$, colourless needle, $0.316 \times 0.073 \times 0.069 \mathrm{~mm}$, monoclinic, space group $P 2_{1} / n$ (No. 14), $a=$ 9.74790(10), $b=18.0343(2), c=19.5010(2) \AA, \beta=96.0760(10)^{\circ}, V=3408.95(6) \AA^{3}, Z=$ 4, $D_{\mathrm{c}}=1.679 \mathrm{~g} \mathrm{~cm}^{-3}, \mu=2.258 \mathrm{~mm}^{-1} . F_{000}=1736$, MoK $\alpha$ radiation, $2 \theta_{\max }=63.73^{\circ}, 37682$ reflections collected, 11067 unique $\left(R_{\text {int }}=0.0377\right)$. Final GooF $=1.055, R 1=0.0328$, $w R 2=0.0760, R$ indices based on 9583 reflections with $I>2 \sigma(I),|\Delta \rho|_{\max }=0.929$ e $\AA^{-3}$, 519 parameters, 14 restraints. CCDC 1920182. 
One solvent was modelled as an acetonitrile molecule. The second site was modelled as a water molecule (site occupancy $0.911(5)$ ) disordered with two partially occupied water molecule each with site occupancies of 1-0.911(5). Hydrogen atoms for the partially weighted water molecules $\mathrm{O} 4$ and $\mathrm{O} 5$ were not located. Except for the minor components of the disordered water molecules, $\mathrm{N}-\mathrm{H}$ and $\mathrm{O}-\mathrm{H}$ hydrogen atoms were located and refined with geometries restrained to ideal values.

$\left(\mathrm{NH}_{4}\right)\left[\mathrm{Ho}(2-4 \mathrm{H})\left(\mathrm{OH}_{2}\right)_{2}\right] \cdot \mathrm{CH}_{3} \mathrm{CN} \cdot 1.10 \mathrm{H}_{2} \mathrm{O}: \mathrm{C}_{34} \mathrm{H}_{37.21} \mathrm{HoN}_{10} \mathrm{O}_{7.10}, M=864.47$, colourless needle, $0.605 \times 0.099 \times 0.080 \mathrm{~mm}$, monoclinic, space group $P 2_{1} / n$ (No. 14), $a=$ 9.74140(10), $b=18.0439(2), c=19.5108(2) \AA, \beta=96.4870(10)^{\circ}, V=3407.51(6) \AA^{3}, Z=$ 4, $D_{\mathrm{c}}=1.685 \mathrm{~g} \mathrm{~cm}^{-3}, \mu=2.388 \mathrm{~mm}^{-1} . F_{000}=1740$, MoK $\alpha$ radiation, $2 \theta_{\max }=68.88^{\circ}, 96396$ reflections collected, 13893 unique $\left(R_{\text {int }}=0.0499\right)$. Final GooF $=1.058, R 1=0.0305$, $w R 2=0.0730, R$ indices based on 12160 reflections with $I>2 \sigma(I),|\Delta \rho|_{\max }=1.810$ e $\AA^{-}$ 3, 519 parameters, 14 restraints. CCDC 1920183.

Refinement details as for the isomorphous Dy salt, with water molecule site occupancy $0.897(4)$.

$\left(\mathrm{NH}_{4}\right)\left[\mathrm{Er}(2-4 \mathrm{H})\left(\mathrm{OH}_{2}\right)_{2}\right] \cdot \mathrm{CH}_{3} \mathrm{CN} \cdot 1.11 \mathrm{H}_{2} \mathrm{O}: \mathrm{C}_{34} \mathrm{H}_{37.22} \mathrm{ErN}_{10} \mathrm{O}_{7.11}, M=866.98$, colourless needle, $0.416 \times 0.117 \times 0.112 \mathrm{~mm}$, monoclinic, space group $P 2_{1} / n$ (No. 14), $a=$ 9.73750(10), $b=18.0725(2), c=19.5073(3) \AA, \beta=96.8510(10)^{\circ}, V=3408.40(7) \AA^{3}, Z=$ 4, $D_{\mathrm{c}}=1.690 \mathrm{~g} \mathrm{~cm}^{-3}, \mu=2.518 \mathrm{~mm}^{-1} . F_{000}=1744$, MoK $\alpha$ radiation, $2 \theta_{\max }=68.89^{\circ}, 97556$ reflections collected, 13875 unique $\left(R_{\text {int }}=0.0389\right)$. Final GooF $=1.070, R 1=0.0298$, $w R 2=0.0738, R$ indices based on 12391 reflections with $I>2 \sigma(I),|\Delta \rho|_{\max }=1.366$ e $\AA^{-}$ 3, 519 parameters, 13 restraints. CCDC 1920184.

Refinement details as for the isomorphous Dy salt, with water molecule site occupancy $0.890(5)$ 
$\left(\mathrm{NH}_{4}\right)\left[\mathrm{Yb}(2-4 \mathrm{H})\left(\mathrm{OH}_{2}\right)_{2}\right] \cdot \mathrm{CH}_{3} \mathrm{CN} \cdot 1.15 \mathrm{H}_{2} \mathrm{O}: \mathrm{C}_{34} \mathrm{H}_{37.31} \mathrm{~N}_{10} \mathrm{O}_{7.15} \mathrm{Yb}, M=873.52$, colourless block, $0.477 \times 0.149 \times 0.110 \mathrm{~mm}$, monoclinic, space group $P 2_{1} / n$ (No. 14), $a=$ 9.75230(10), $b=18.0935(2), c=19.4719(2) \AA, \beta=97.4600(10)^{\circ}, V=3406.80(6) \AA^{3}, Z=$ 4, $D_{\mathrm{c}}=1.703 \mathrm{~g} \mathrm{~cm}^{-3}, \mu=2.811 \mathrm{~mm}^{-1} . F_{000}=1754$, MoK $\alpha$ radiation, $2 \theta_{\max }=66.00^{\circ}, 99183$ reflections collected, 12833 unique $\left(R_{\text {int }}=0.0421\right)$. Final GooF $=1.051, R 1=0.0253$, $w R 2=0.0624, R$ indices based on 11565 reflections with $I>2 \sigma(I),|\Delta \rho|_{\max }=1.394$ e $\AA^{-}$ 3, 519 parameters, 14 restraints. CCDC 1920185.

Refinement details as for the isomorphous Dy salt, with water molecule site occupancy $0.847(4)$.

Complexes of $\mathbf{3}$ crystallised from ethanol/ethyl acetate

$\left\{\left(\mathrm{NH}_{4}\right)[\mathrm{Eu}(3-4 \mathrm{H})(\mathrm{HOEt})] \cdot 2 \mathrm{EtOH} . \mathrm{H}_{2} \mathrm{O}\right\}_{n}: \mathrm{C}_{50} \mathrm{H}_{64} \mathrm{EuN}_{9} \mathrm{O}_{8}, M=1071.06$, orange needle, $0.227 \times 0.067 \times 0.044 \mathrm{~mm}$, monoclinic, space group $C c$ (No. 9), $a=23.4393(14), b=$ 22.1593(12), $c=9.7424(5) \AA, \beta=101.163(5)^{\circ}, V=4964.4(5) \AA^{3}, Z=4, D_{c}=1.433 \mathrm{~g} \mathrm{~cm}^{-}$ ${ }^{3}, \mu=9.550 \mathrm{~mm}^{-1} . F_{000}=2216$, CuK $\alpha$ radiation, $2 \theta_{\max }=136.0^{\circ}, 21998$ reflections collected, 6953 unique $\left(R_{\text {int }}=0.1029\right)$. Final $G o o F=1.044, R 1=0.0706, w R 2=0.1721$, $R$ indices based on 5779 reflections with $I>2 \sigma(I),|\Delta \rho|_{\max }=2.813$ e $\AA^{-3}, 637$ parameters, 21 restraints. CCDC 1920186.

$\mathrm{OH}$ and $\mathrm{NH}$ hydrogen atoms of the coordinated ethanol molecule, the water molecule and the ammonium ion were refined with geometries restrained to ideal values.

$\left\{\left(\mathrm{NH}_{4}\right)[\mathrm{Eu}(3-4 \mathrm{H})(\mathrm{HOEt})] \cdot 3 \mathrm{EtOH}\right\}_{n}: \mathrm{C}_{52} \mathrm{H}_{68} \mathrm{EuN}_{9} \mathrm{O}_{8}, M=1099.11$, orange needle, 0.304 $\times 0.132 \times 0.064 \mathrm{~mm}$, monoclinic, space group CC (No. 9), $a=23.2329(5), b=22.7796(6)$, $c=9.7291(2) \AA, \beta=99.268(2)^{\circ}, V=5081.8(2) \AA^{3}, Z=4, D_{c}=1.437 \mathrm{~g} \mathrm{~cm}^{-3}, \mu=9.344 \mathrm{~mm}^{-}$ 1. $F_{000}=2280$, CuK $\alpha$ radiation, $2 \theta_{\max }=134.7^{\circ}, 22822$ reflections collected, 7628 unique $\left(R_{\text {int }}=0.0454\right)$. Final $G o o F=1.049, R 1=0.0490, w R 2=0.1251, R$ indices based on 7084 
reflections with $I>2 \sigma(I),|\Delta \rho|_{\max }=1.677$ e $\AA^{-3}, 673$ parameters, 24 restraints. CCDC 1920188.

$\mathrm{OH}$ and $\mathrm{NH}$ hydrogen atoms of the coordinated ethanol molecule, and the ammonium ion were refined with geometries restrained to ideal values.

$\left\{\left(\mathrm{NH}_{4}\right)[\mathrm{Gd}(3-4 \mathrm{H})(\mathrm{HOEt})] \cdot 3 \mathrm{EtOH}\right\}_{n}: \mathrm{C}_{52} \mathrm{H}_{68} \mathrm{GdN}_{9} \mathrm{O}_{8}, M=1104.40$, yellow needle, 0.323 x $0.064 \times 0.063 \mathrm{~mm}$, monoclinic, space group $C c$ (No. 9), $a=23.1932(8), b=$ 22.7649(12), $c=9.7153(3) \AA, \beta=99.017(3)^{\circ}, V=5066.2(4) \AA^{3}, Z=4, D_{c}=1.448 \mathrm{~g} \mathrm{~cm}^{-3}$, $\mu=8.978 \mathrm{~mm}^{-1} . F_{000}=2284$, CuK $\alpha$ radiation, $2 \theta_{\max }=135.5^{\circ}, 22339$ reflections collected, 7584 unique $\left(R_{\text {int }}=0.0570\right)$. Final $G o o F=1.014, R 1=0.0581, w R 2=0.1500$, $R$ indices based on 6790 reflections with $I>2 \sigma(I),|\Delta \rho|_{\max }=2.023$ e $\AA^{-3}, 673$ parameters, 25 restraints. CCDC 1920189.

Refinement details as for the Eu analogue

\section{Conflicts of Interest}

There are no conflicts to declare.

\section{Acknowledgements}

This research was partially supported by the Australian Research Council's Discovery Projects funding scheme (project DP17010189). R.Z.H.P. thanks Curtin University for the postgraduate scholarship.

\section{References}

[1] a) Z. Zheng, in Handbook on the Physics and Chemistry of Rare Earth Elements, Vol. 40 (Eds.: K. A. Gschneider Jr, J.-C. Bünzli, V. K. Pecharsky), Elsevier, Amsterdam, 2010, p. 
109; b) A. T. Wagner, P. W. Roesky, Eur. J. Inorg. Chem. 2016, 782-791; c) G. Calvez, F. Le Natur, C. Daiguebonne, K. Bernot, Y. Suffren, O. Guillou, Coord. Chem. Rev. 2017, 340, 134-153.

[2] D. D'Alessio, A. N. Sobolev, B. W. Skelton, R. O. Fuller, R. C. Woodward, N. A. Lengkeek, B. H. Fraser, M. Massi, M. I. Ogden, J. Am. Chem. Soc. 2014, 136, 15122-15125.

[3] D. D’Alessio, S. Muzzioli, B. W. Skelton, S. Stagni, M. Massi, M. I. Ogden, Dalton Trans. 2012, 41, 4736-4739.

[4] M. Massi, S. Stagni, M. I. Ogden, Coord. Chem. Rev. 2018, 375, 164-172.

[5] a) A. Bilyk, J. W. Dunlop, R. O. Fuller, A. K. Hall, J. M. Harrowfield, M. W. Hosseini, G. A. Koutsantonis, I. W. Murray, B. W. Skelton, R. L. Stamps, A. H. White, Eur. J. Inorg. Chem. 2010, 2106-2126; b) W. Q. Lin, X. F. Liao, J. H. Jia, J. D. Leng, J. L. Liu, F. S. Guo, M. L. Tong, Chem. Eur. J. 2013, 19, 12254-12258; c) Y. L. Miao, J. L. Liu, J. Y. Li, J. D. Leng, Y. C. Ou, M. L. Tong, Dalton Trans. 2011, 40, 10229-10236; d) S. M. Taylor, S. Sanz, R. D. McIntosh, C. M. Beavers, S. J. Teat, E. K. Brechin, S. J. Dalgarno, Chem. Eur. J. 2012, 18, 16014-16022; e) M. D. Ward, Chem. Commun. 2009, 4487-4499.

[6] a) S. P. Argent, A. Greenaway, M. D. Gimenez-Lopez, W. Lewis, H. Nowell, A. N. Khlobystov, A. J. Blake, N. R. Champness, M. Schroder, J. Am. Chem. Soc. 2012, 134, 55-58; b) F. S. Guo, Y. C. Chen, L. L. Mao, W. Q. Lin, J. D. Leng, R. Tarasenko, M. Orendac, J. Prokleska, V. Sechovsky, M. L. Tong, Chem. Eur. J. 2013, 19, 14876-14885; c) S. Pasquale, S. Sattin, E. C. Escudero-Adan, M. Martinez-Belmonte, J. de Mendoza, Nat. Comm. 2012, 3.

[7] a) C.-Y. Cheng, T. C. Stamatatos, G. Christou, C. R. Bowers, J. Am. Chem. Soc. 2010, 132, 5387-5393; b) N. Hoshino, A. M. Ako, A. K. Powell, H. Oshio, Inorg. Chem. 2009, 48, 3396-3407; c) P. King, T. C. Stamatatos, K. A. Abboud, G. Christou, Angew. Chem. Int. Ed. 2006, 45, 7379-7383.

[8] K. Koguro, T. Oga, S. Mitsui, R. Orita, Synthesis-Stuttgart 1998, 910-914.

[9] Y. J. Chen, W. S. Chung, Eur. J. Org. Chem. 2009, 4770-4776.

[10] J. L. Atwood, L. J. Barbour, A. Jerga, J. Am. Chem. Soc. 2002, 124, 2122-2123.

[11] R. G. Lin, L. S. Long, R. B. Huang, L. S. Zheng, Inorg. Chem. Commun. 2007, 10, 12571261.

[12] a) G. Brancatelli, S. Pappalardo, G. Gattuso, A. Notti, I. Pisagatti, M. F. Parisi, S. Geremia, Crystengcomm 2014, 16, 89-93; b) G. Brancatelli, G. Gattuso, S. Geremia, N. Manganaro, A. Notti, S. Pappalardo, M. F. Parisi, I. Pisagatti, Crystengcomm 2015, 17, 7915-7921; c) G. Brancatelli, G. Gattuso, S. Geremia, A. Notti, S. Pappalardo, M. F. Parisi, I. Pisagatti, Org. Lett. 2014, 16, 2354-2357; d) G. Gattuso, A. Notti, S. Pappalardo, M. F. Parisi, T. Pilati, G. Terraneo, Crystengcomm 2012, 14, 2621-2625; e) G. Brancatelli, G. Gattuso, S. Geremia, N. Manganaro, A. Notti, S. Pappalardo, M. F. Parisi, I. Pisagatti, Crystengcomm 2016, 18, 5012-5016; f) C. Capici, G. Gattuso, A. Notti, M. F. Parisi, S. Pappalardo, G. Brancatelli, S. Geremia, J. Org. Chem. 2012, 77, 9668-9675; g) G. Gattuso, A. Notti, S. Pappalardo, M. F. Parisi, T. Pilati, G. Resnati, G. Terraneo, Crystengcomm 2009, 11, 1204-1206.

[13] a) F. F. Nachtigall, M. Lazzarotto, E. E. Castellano, F. Nome, Supramol. Chem. 2004, 16, 453-458; b) M. Lazzarotto, C. I. Ferreira, E. E. Castellano, A. V. Veglia, J. Mol. Struct. 2014, 1067, 88-93.

[14] U. Radius, J. Attner, Eur. J. Inorg. Chem. 1998, 299-303.

[15] L. Semenova, B. Skelton, A. White, Aust. J. Chem. 1996, 49, 997-1004.

[16] G. M. Sheldrick, Acta Crystallogr. Sect. C: Struct. Chem. 2015, 71, 3-8. 
